\title{
EN LOS BORROSOS CONFINES DE LA LIBERTAD: EL CASO DE LOS NEGROS EMANCIPADOS EN CUBA, 1817-1870*
}

\author{
POR \\ INÉS ROLDÁN DE MONTAUD \\ Instituto de Historia-CCHS \\ Consejo Superior de Investigaciones Científicas
}

«Está condenado a la servidumbre perpetua por haber tenido la desgracia de no ser esclavo».

Porfirio Valiente, 1869.

En este artículo estudiamos el grupo de africanos llevados a Cuba para convertirse en esclavos y que fueron declarados jurídicamente libres por haber sido capturado el buque que los transportaba, en aplicación de los tratados internacionales y la presión abolicionista británica. Los llamados negros emancipados, unos 26.000 individuos, fueron sin embargo asimilados a la población esclava ante el temor de que pudieran resultar un factor disolvente del orden social, debido a la necesidad de mano de obra para el azúcar y a la aparición de un lucrativo negocio para las autoridades. El estudio aborda la situación del grupo desde sus orígenes en 1817 hasta su desaparición en 1870.

Palabras clave: Emancipados, esclavitud, abolicionismo, Cuba.

\section{EL ORIGEN DE LOS NEGROS EMANCIPADOS}

Desde 1807 Gran Bretaña se pronunció contra el tráfico de esclavos y se dispuso a suprimirlo del mundo atlántico. Con dicha finalidad, el 23 de sep-

* Este artículo se inscribe en el proyecto HAR2009-07103 «Diccionario biográfico español de ministros de Ultramar». 
tiembre de 1817 logró arrancar a Fernando VII la firma de un tratado en el que se prohibía a los súbditos españoles ocuparse en el tráfico de esclavos en cualquier punto de la costa africana desde finales de mayo de 1820 y al sur del Ecuador desde el canje de las ratificaciones del tratado. Se autorizaba a los buques de guerra de las partes contratantes a registrar los mercantes de ambos países cuando se sospechase que llevaban a bordo esclavos de ilícito comercio. De encontrarse negros, los buques serían detenidos y juzgados por comisiones mixtas que se crearían en La Habana y en Sierra Leona, que decidirían sobre la legalidad de la presa realizada sin posible apelación.

Conforme al artículo XIII del tratado y VII de su anejo para la regulación de las comisiones mixtas, en caso de condena de un buque los esclavos hallados a bordo recibirían un certificado de emancipación y serían entregados al gobierno en cuyo territorio residiera la comisión que hubiera pronunciado la sentencia, para que los empleara como criados o trabajadores libres. Ambos gobiernos se obligaban a garantizar la libertad de los individuos que les fuesen entregados ${ }^{1}$. Poco después, la Real Cédula de 19 de diciembre de 1817 puso en efecto el tratado, prohibiendo a los súbditos españoles ocuparse en el tráfico en las costas africanas. Los negros comprados en dichas costas serían declarados libres en el primer punto de los dominios españoles a los que llegasen las embarcaciones que los transportaban ${ }^{2}$.

En ambos textos radica el origen legal de los llamados negros emancipados. La voz emancipación — según aseguraba el jurista Zamora y Coronado- era desconocida hasta entonces en el diccionario español y se utilizó por primera vez en el tratado ${ }^{3}$. El azar de ser capturados por cruceros de guerra o descubiertos por las autoridades de Cuba en el momento del desembarco convertía en hombres libres a aquellos seres abocados a ser esclavos. Nacido de un acuerdo internacional, el grupo emancipado era un cuerpo extraño en el seno de la sociedad esclavista: no se trataba de un esclavo porque así lo establecía la ley; pero tampoco podía dejar de serlo porque así lo requería el mantenimiento del orden social existente en la colonia, que exigía que los esclavos y quienes tuvieran su origen en la esclavitud, y por extensión en África, fuesen mantenidos en su lugar y subordinados ${ }^{4}$. De ahí que en aquella sociedad se contemplara al grupo de negros y mulatos libres con creciente preocupación a medida que aumentaba la población negra de la isla en relación con la blanca y que el acceso de los esclavos a la condición civil de hombres libres no fuera sencillo.

1 El texto completo en Pezuela, 1863, II: 286-291.

2 Fernando Ortiz, 1975: 424-426.

3 Zamora y Coronado, 1845, III: 84.

4 Entre muchos otros, Martínez Alier, 1979: 19. Klein, 1986: 140. 
Lo cierto es que la incorporación a la sociedad cubana como hombres libres de los poco más de 26.000 negros a quienes se declaró emancipados entre 1824 y 1866 se demostró casi imposible (cuadro I). Se estima que entre 1817 y 1873 se introdujeron clandestinamente en Cuba unos 340.000 esclavos, de modo que el número de los que fueron capturados y declarados emancipados apenas representó un 7,6\%. A pesar de su escasa importancia numérica, la presencia del grupo planteó una serie de problemas de gran alcance. Su existencia se percibía como un elemento extremadamente peligroso para el mantenimiento del orden social. De hecho, durante décadas el asunto de los emancipados se convirtió en objeto esencial de discusión entre los gobiernos británico y español en torno a la cuestión de la abolición del tráfico.

Aunque existen numerosos estudios sobre la sociedad esclavista cubana, esta nueva categoría de negros a la que el historiador y publicista español Jacobo de la Pezuela describió como «nueva clase de color que no era sierva ni podía aun dejar de serlo», y a la que David Murray, uno de sus primeros estudiosos, se refirió como «new class of slaves» ${ }^{5}$, ha merecido escasa atención ${ }^{6}$. En este artículo se contemplan las circunstancias que dieron lugar a su nacimiento, las condiciones en las que transcurrió su existencia en el seno de una sociedad racialmente conflictiva, que inicialmente reaccionó adoptando una serie de proyectos de expulsión y posteriormente asimilándolo completamente al sector esclavo de la población. Quedan fuera de nuestro actual alcance aspectos tan esenciales como los relacionados con el grado de percepción que los emancipados tuvieron de su situación y su lucha por hacer real y efectiva la libertad que jurídicamente se les había reconocido, que algunos emprendieron con el apoyo de los diplomáticos británicos residentes en La Habana.

La trayectoria de este pequeño grupo humano no puede contemplarse como un hecho aislado sino como la expresión de un fenómeno de dimensión atlántica o incluso global. La existencia de negros emancipados se registra en todos aquellos lugares en los que Gran Bretaña forzó la firma de tratados contra la trata de africanos, incluso en las propias colonias británicas desde que dicho país abolió el tráfico en 18077 . Si el caso de los «africanos livres» brasileños es para nosotros de particular interés por la similitud que guarda con el

5 Pezuela, 1863, II: 293. Murray, 1980.

6 Bethell, 80 (Londres, 1966): 79-93. Franco, 1980: 342-360. Murray, 1980: 269-297. Roldán de Montaud, 57 / 169-170 (Madrid, 1982): 559-641. Martínez-Fernández, 16 / 2 (Londres, 1995): 27-50; 1998: 41-64.

7 Thompson, 2002: 7. 
Cuadro I. Expediciones de negros bozales capturados en las Costas de la isla de Cuba

\begin{tabular}{|c|c|c|c|c|c|}
\hline Año & Expedición & Núm. & Año & Expedición & Núm. \\
\hline 1824 & Relámpago & 150 & 1853 & Bermeja & 134 \\
\hline \multirow{5}{*}{1826} & Cayo verde & 61 & 1854 & Caleta del Rosario & 15 \\
\hline & Campeador & 229 & & Cayo Livisa & 261 \\
\hline & Fingal & 58 & & Matanzas & 113 \\
\hline & Orestes & 212 & & Pinar del Río & 185 \\
\hline & Mágico & 176 & & Ortigosa & 202 \\
\hline \multirow{3}{*}{1828} & Gerges & 395 & & Güines & 161 \\
\hline & Firme & 484 & & Manimani & 103 \\
\hline & Intrépido & 135 & & Isla de Pinos & 242 \\
\hline \multirow[t]{4}{*}{1829} & Josefa & 206 & & Mariel & 70 \\
\hline & Voladora & 331 & & Brujas. Luisa & 589 \\
\hline & Midas & 281 & & S. Ëspíritus y Trinidad & 743 \\
\hline & Gallito & 135 & 1855 & Santa Cruz & 42 \\
\hline \multirow[t]{2}{*}{1830} & Emilio & 188 & & Punta de Ganado & 74 \\
\hline & Santiago & 105 & & Guanajay-Bahía Honda & 93 \\
\hline \multirow[t]{3}{*}{1832} & Águila & 601 & & Nuevas Grandes & 25 \\
\hline & Indagadora & 134 & 1856 & Bahía Honda & 49 \\
\hline & Planeta & 238 & 1857 & Sancti Espíritus & 55 \\
\hline 1833 & Negrito & 490 & & Almedares & 21 \\
\hline \multirow[t]{3}{*}{1834} & Rosa & 322 & & Jaruco & 91 \\
\hline & Joaquina & 479 & & Morro & 85 \\
\hline & Manuelita & 200 & & Páez & 356 \\
\hline \multirow[t]{10}{*}{1835} & Amalia & 193 & & Primer Neptuno & 534 \\
\hline & Carlota & 253 & & Leckihgton & 497 \\
\hline & Chubasco & 72 & & Santa Susana & 29 \\
\hline & Holguín & 254 & & Sagua Pelada & 3 \\
\hline & Joven Reina & 341 & & Guadalquizal & 1 \\
\hline & María & 290 & 1858 & Lanzanillo & 497 \\
\hline & Marte & 403 & & Guantánamo & 361 \\
\hline & Julita & 340 & & Punta de Guano & 190 \\
\hline & Tita & 393 & & Venadito & 615 \\
\hline & Diligencia & 205 & 1859 & Blasco de Garay & 438 \\
\hline \multirow[t]{2}{*}{1836} & Ninfa & 432 & 1860 & Gibacoa & 47 \\
\hline & Ricomar & 186 & & Luisa & 142 \\
\hline 1841 & Portugués (Cabañas) & 411 & & Cayo Cádiz & 562 \\
\hline \multirow[t]{8}{*}{1842} & Majana & 150 & & Segundo Neptuno & 419 \\
\hline & Aurelia Feliz & 158 & & Cayo Sal & 846 \\
\hline & Demayajabos & 84 & & Casilda & 71 \\
\hline & San Marcos & 47 & 1861 & Manatí & 396 \\
\hline & Macambo & 152 & & Juanita & 69 \\
\hline & Yumuría & 90 & & Yateras & 40 \\
\hline & Caleta de Barca & 15 & & Maniabón & 49 \\
\hline & Punta de Maya & 10 & & Santa María & 621 \\
\hline 1843 & Puerto Escondido & 85 & 1862 & Cabo Indio & 281 \\
\hline 1846 & Cabañas & 10 & 1863 & Agüica & 1.031 \\
\hline 1847 & Trinidad & 134 & & Domínica & 53 \\
\hline \multirow[t]{2}{*}{1849} & Cabañas & 85 & & Manaca & 418 \\
\hline & Santa Clara & 172 & & Canao, Sagua y Bomaniel & 216 \\
\hline 1851 & Cárdenas & 402 & 1864 & Lezo & 365 \\
\hline 1852 & Granadilla & 25 & & Guadalquivir & 469 \\
\hline \multirow[t]{3}{*}{1853} & Cárdenas y Matanzas & 275 & & Tercer Neptuno & 365 \\
\hline & Remedios & 52 & 1865 & Gato & 140 \\
\hline & Sagua la Grande & 16 & 1866 & Punta Holanda & 278 \\
\hline Total & & & & & 26.026 \\
\hline
\end{tabular}

Fuente: Secretaría de Gobierno de Cuba, 12 de diciembre de 1870, AHN, Estado, legajo 8554.

Para el periodo 1824-1841 se dispone de otro Estado de los buques españoles apresados por otros de guerra de S.M.B., 29 de junio de 1841, AHN, Estado, legajo 8040. Existen notables diferencias en el número de esclavos de cada buque e incluso en el año de captura. 
cubano $^{8}$, lo cierto es que hubo también «Liberated africans», expresión con la que se designaba a los emancipados en el mundo anglosajón, en lugares tan distantes como Sierra Leona, las Antillas británicas, los Estados Unidos, El Cabo o Mauricio, en el Índico, entre otros. Para referirse a esta nueva categoría social la historiografía reciente ha acuñado el término «recaptive africans», por entender que es el que mejor refleja la situación de unos individuos que rara vez llegaron a disfrutar de la libertad después de haber sido liberados de los barcos negreros, de unos individuos que por doquier corrieron una suerte parecida, bien convertidos en trabajadores forzados, en apprenticed o indentured labour, bien reducidos lisa o llanamente a la esclavitud. Se ha estimado que desde 1807 los británicos sustrajeron del tráfico ilegal a unos 160.000 seres humanos. El grupo de los emancipados cubanos forma parte de este colectivo9.

La primera captura realizada por un crucero británico en aguas cubanas se produjo el 18 de diciembre de 1824 (cuadro I). Pocos días después, la comisión mixta de La Habana declaró emancipados a los 147 negros conducidos por el Relámpago y los entregó, con su correspondiente certificado, al capitán general Dionisio Vives. El general no había recibido instrucciones de Madrid $\mathrm{y}$, de momento, los depositó en un caserío de las afueras de Regla en el que habitualmente se guardaba a los cimarrones. Luego los distribuyó entre algunos vecinos y diversos establecimientos piadosos y de enseñanza pública de $\mathrm{La}$ Habana, conforme a unas condiciones que preparó el juez comisionado británico J. T. Kilbee, similares a las que se aplicaban en las colonias británicas, y que Vives aceptón ${ }^{10}$.

La presencia de estos negros planteaba una serie de problemas que en principio se intentaron solucionar mediante la expulsión. La posibilidad de que en breve fueran a engrosar la comunidad de los libres de color, que rondaba los 100.000 individuos, y sirvieran de ejemplo a los más de 290.000 esclavos

8 Para el caso brasileño, Conrad, 53 / 1 (Durham, 1973): 50-70. Gallotti Mamigonian, 2005: 389-417 (Londres, 2009b): 41-66.

9 Schuler, 2001: 134. Véanse Schuler, 1980. James, 1991. Carter, 2003. Gbarie, 2010. Una muestra de la importancia de esta historiografía en las ponencias presentadas al congreso «Liberated africans as Human Legacy of Abolition», International Workshop, University of California, mayo 2008.

10 Condiciones con que se reparten por el gobierno los negros que se han emancipado, conducidos a este puerto en el bergantín español Relámpago, apresado por la goleta Lion de S.M.B. conforme al artículo séptimo del reglamento para las Comisiones mixtas establecidas en esta plaza; en cumplimiento del tratado de 1817 para la abolición de tráfico de esclavos, La Habana, Oficina del Gobierno y Capitanía General por S. M., 1824. Padece un error Franco al creer que las condiciones de reparto las dictó Vives en 1828, Franco, 1980: 344. 
existentes era un asunto que despertaba profundos temores en las autoridades y en la oligarquía esclavista de plantadores y traficantes. Con ocasión del apresamiento del Relámpago, el general Vives escribía a Madrid alarmado. Advertía de que era sumamente perjudicial y de pésimo ejemplo para los esclavos que los negros emancipados permanecieran en la isla. En su opinión, había que devolverlos a sus lugares de origen a costa de quienes los habían conducido a Cuba ${ }^{11}$. Claudio Martínez de Pinillos, superintendente de la Real Hacienda y juez español de la comisión mixta, propuso poco después que los negros se cedieran al gobierno británico para que los trasladara a Jamaica. Aseguraba que la población libre de color era ya muy numerosa en las poblaciones en proporción a la blanca y que de los emancipados sólo se podía «esperar mal ejemplo para los esclavos de las haciendas si a ellas se destinan bajo condiciones desiguales y corrupción en las poblaciones, donde reinan los vicios señalados en los de su clase» ${ }^{12}$.

Para evitar el aumento de la clase de los negros libres que se derivaría del cumplimiento del tratado, en octubre de 1826 el ayuntamiento de La Habana propuso que el gobierno gestionase la reforma del mencionado artículo VII y que los buques capturados fueran conducidos a África y juzgados por la comisión de Sierra Leona ${ }^{13}$. No era «cordura» poner a los negros esclavos con otros que al fin eran libres, advertía. La noticia de su condición daría «infaliblemente lugar a reflexiones, contrastes, cuyos funestos resultados no sería muy difícil prever». Ante semejante estado de alarma y después de someter la cuestión a consulta del Consejo de Estado, por real orden de abril de 1828 se dispuso que los emancipados fueran enviados a otros dominios de su majestad, incluida la propia península, con cargo al producto de los barcos capturados y enajenados que pudiera corresponder a España. Se anunciaban negociaciones con Gran Bretaña para modificar el artículo VII ${ }^{14}$. Parece que esta disposición no llegó a cumplirse ${ }^{15}$.

Las negociaciones con Inglaterra se aceleraron cuando en junio de 1832 la comisión mixta condenó al Aguila y declaró libres a los 601 negros que lleva-

11 Vives al secretario de Estado y Despacho, 6 de enero de 1825, Archivo Histórico Nacional, Madrid (AHN), Ultramar, legajo 3549, exp. 19. Murray, 1980: 275-276.

12 Martínez de Pinillos al Consejo de Indias, 15 de marzo de 1825, AHN, Ultramar, legajo 3549, exp. 7.

13 Exposición del ayuntamiento de la Habana, 13 de octubre de 1826, AHN, Ultramar, legajo 3547 , exp. 7.

14 Acuerdo de Consejo de Estado, 4 de febrero de 1828, AHN, Ultramar, legajo 3547, exp. 7. Fontana, XVII / 2 (La Habana, 1975): 89-98. Real Orden de 15 de abril de 1828, reiterada en diciembre y de nuevo a principios de 1830, AHN, Estado, legajo 8034.

15 Erénchun, 1858, II: 952. 
ba a bordo. El número de negros emancipados se aproximó entonces a 3.000. A principios de 1833, en vísperas de que el parlamento hubiera aprobado el acta de emancipación de los esclavos, Inglaterra se comprometió a recibir en Trinidad a los negros que en el futuro fueran emancipados y los que lo hubieran sido en los dos últimos años, siempre y cuando los gastos corrieran por cuenta del gobierno español y se cumplieran otra serie de requisitos ${ }^{16}$. Los 196 bozales capturados a bordo del Negrito fueron los primeros emancipados enviados a Trinidad, en mayo de 1833. Parece que la propagación de la epidemia de cólera que diezmaba la población precipitó la decisión. En enero de 1834 se embarcaron los 212 apresados en las goletas Joaquina y Manuelita; en febrero, los 193 de la Rosa. En total fueron trasladados 987 negros de los 5.245 capturados hasta entonces ${ }^{17}$. El precio de los bozales oscilaba entonces entre 200 y 300 pesos; se trataba, por consiguiente, de un momento en que la preocupación por evitar el crecimiento de la población libre pesaba más que la posible pérdida de mano de obra todavía relativamente abundante y barata. La entrega de emancipados a las autoridades británicas no duró, no obstante, mucho tiempo. Cesó poco después de la llegada del general Tacón a Cuba ${ }^{18}$. Fue precisamente entonces cuando el reparto de emancipados comenzó a realizarse a cambio de importantes sumas, capaces de enriquecer a funcionarios venales y de proporcionar recursos para costear la ejecución de diversas obras públicas, tarea a la que se entregó con pasión el general Tacón ${ }^{19}$.

Las dificultades que encontraba la regente María Cristina para defender los derechos de su hija al trono obligaron a un acercamiento al gobierno británico. A cambio de apoyo España se avino a firmar un nuevo tratado contra la trata de esclavos, que seguían arribando a Cuba por millares con la complicidad de las autoridades (unos 66.000 entre 1821 y 1831$)^{20}$. En el tratado de 28 de junio de 1835 se modificaba el artículo VII del de 1817 en el sentido deseado por España, que cuadraba perfectamente a los intereses británicos. A partir de en-

16 Nota del conde de Villanueva a los comisionados británicos, 23 de enero de 1833, y Condiciones para el traslado de emancipados a Trinidad, 16 de enero de 1833, AHN, Estado, legajo 8034, exp. 6. Para las negociaciones, Murray, 1980: 277-279.

$17 \mathrm{La}$ abundante correspondencia que produjeron estos envíos en AHN, Estado, legajos 8023 y 8025 . Adderley, 2006, para el asentamiento de estos emancipados en las Antillas británicas.

18 Tacón al secretario de Estado, 29 de diciembre de 1835, AHN, Estado, legajo 8015, exp. 29.

19 Roldán de Montaud, 57 / 169-170 (Madrid, 1982): 574-577.

20 En cualquier caso, como sólo autorizaba a los cruceros españoles y británicos a interceptar buques de estas dos nacionalidades y brasileños, se demostró también un instrumento ineficaz para reprimir el tráfico que se realizaba bajo bandera norteamericana. 
tonces, los esclavos a bordo de un buque condenado no se entregarían al gobierno del territorio donde residiera la Comisión que lo juzgara sino al gobierno del país cuyo crucero hubiera hecho la presa.

El gobierno al que compitiera la responsabilidad de los emancipados se comprometía a ponerlos en libertad, mantenerlos en ella y proporcionar noticias sobre su situación cuando lo requiriera la otra parte contratante ${ }^{21}$. El tratado incorporaba un anexo en el que se establecían las condiciones de trato de los emancipados. Nada se decía sobre los límites del periodo de aprendizaje; se indicaba únicamente que el gobierno español se obligaba a que fueran tratados conforme a los reglamentos existentes. De modo que seguirían distribuyéndose en las mismas condiciones que hasta entonces. Sin embargo, para evitar que los bozales quedaran reducidos a esclavitud se dispuso la creación de un registro general de emancipados en el que debían anotarse los nombres, las circunstancias de los negros y los consignatarios. Cada seis meses se entregaría un estado de la situación de los emancipados al tribunal mixto. En definitiva, el nuevo tratado incorporaba una regulación más amplia que el de 1817 y proporcionó instrumentos que sirvieron de cauce a una permanente presión de las autoridades británicas.

Como España apenas tenía buques dedicados a la persecución de la trata, en adelante prácticamente todos los negros emancipados por el tribunal de La Habana serían responsabilidad del gobierno británico y, por consiguiente, no permanecerían en la isla. Una de las consecuencias de este acuerdo fue la aparición de la figura del superintendente de africanos liberados, que debía hacerse cargo de los negros apresados por cruceros británicos mientras se dictara sentencia. El nombramiento recayó en Richard Robert Madden en 183622. Al año siguiente, Inglaterra consiguió anclar en la bahía de La Habana el famoso pontón Romney para alojar a dichos negros, con la consiguiente secuela de denuncias y acusaciones mutuas entre las autoridades de ambos países ${ }^{23}$. Lo cierto fue que después de 1835 los cruceros británicos se concentraron preferentemente en aguas africanas y el tribunal de La Habana apenas realizó condenas.

El grupo de emancipados cubanos no se limitó a los negros capturados por cruceros británicos y españoles entre 1820 y 1835 y a los que desde entonces lo fueron por buques españoles; incluía también a los negros sorprendidos por las autoridades locales en el momento del desembarco o en tierra conforme a la Real Cédula de 1817, es decir, a los negros que eran emancipados en virtud de las leyes internas vigentes en Cuba. La cuestión se planteó por primera vez

21 Ferrer de Couto, 1864: 113-132.

22 Pérez de la Riva, 1963: 252-255. Madden, 1840; 1849.

23 AHN, Ultramar, legajo 3035. Véase, Philip, 1998: 21-22. 
en 1826, cuando el Mágico encalló y la tripulación se fugó con parte de los bozales. La comisión mixta declaró de buena presa el buque y opinó que los esclavos que había conducido también debían beneficiarse de la libertad. Poco después se reunió el Consejo de Indias para discutir la cuestión y estableció que en tales casos las autoridades debían perseguir a los negros en tierra sin molestar a los dueños de esclavos en sus fincas y que competía al capitán general decidir el futuro de los negros ${ }^{24}$.

La primera captura realizada por las autoridades cubanas tuvo lugar en 1841. En mayo se recogieron en Cabañas 413 bozales desembarcados por el bergantín Portugués (cuadro I). Los negros fueron enviados a La Habana y el expediente correspondiente remitido a la comisión mixta, que lo devolvió para que se procediera conforme a las leyes del país. El general Jerónimo Valdés declaró emancipados a los esclavos y su decisión fue aprobada en Madrid. La real orden de 3 de mayo de 1853 recordaría que el capitán general estaba facultado para perseguir en tierra el tráfico de negros, examinarlos y proceder a su emancipación con arreglo a las leyes ${ }^{25}$. En cualquier caso, lo ocurrido con varios cientos de niños desembarcados en Nuevitas en 1855 ilustra sobradamente sobre las dificultades y presiones con las que tropezaron las autoridades locales en las escasas ocasiones en las que estuvieron dispuestas a cumplir la legalidad ${ }^{26}$.

\section{LAS CONDICIONES DE VIDA DE LOS NEGROS EMANCIPADOS}

Tan pronto como se dictaba sentencia, los emancipados eran distribuidos entre los vecinos y corporaciones de La Habana para que los emplearan como criados mientras supuestamente se instruían en la religión y adquirían un oficio, conforme a las condiciones de reparto mencionadas anteriormente. La consignación de los adultos duraba cinco años; siete, la de las mujeres con hijos que no

24 Consulta al Consejo de Indias, 7 de septiembre de 1826, AHN, Estado, legajo 2022.

25 Hubo juristas que cuestionaron la facultad reconocida a los capitanes generales de determinar la condición de esclavitud o libertad porque además de ser jueces legos, no se sujetaban a ninguna norma para sustanciar el expediente, no estaban obligados a oír a los interesados, ni a veces tenían en cuenta más que las primeras diligencias practicadas en el momento de la aprehensión. Por otra parte, podía dar lugar a soluciones encontradas con las sentencias dictadas por los tribunales en las causas criminales que se seguían a toda introducción fraudulenta de esclavos, que competía en primera y segunda instancia a la Audiencia. De ahí que en la mencionada real orden se encargara a los gobernadores que evitasen que sus resoluciones se encontraran en oposición con las sentencias de los tribunales, Erénchun, 1858, II: 1436-1437.

26 Arnalte, 2001. 
pudieran trabajar y la de los menores. En Brasil la consignación tenía una duración de 14 años, prácticamente la vida útil de un esclavo ${ }^{27}$. Se entendía que concluida la etapa de aprendizaje estarían en condiciones de valerse por sí mismos y obtendrían su preciada carta de libertad, liberándose de la tutela del gobierno e incorporándose a la sociedad como hombres enteramente libres.

Un mes después de efectuadas las primeras consignaciones, en abril de 1825, se reunió en Madrid el Consejo de Indias para estudiar la cuestión. Recomendó, entre otras cosas, que se distribuyeran evitándose, cuanto fuese posible, «colocarlos con dueños de crecido número de esclavos». Se presentía ya el fatal destino de aquellos negros. Lo cierto es que en un principio se repartieron entre los vecinos de La Habana y se entregaron también a diversas corporaciones públicas, exactamente como en Brasil. De los 2.380 emancipados existentes en 1831, 374 se habían puesto a disposición de diversas corporaciones. Varios habían sido cedidos al convento de Ursulinas, al Hospital de San Juan de Dios, a un colegio de niñas y al Apostadero de Marina como fogoneros y paleadores en los buques de guerra ${ }^{28}$. En 1842 el general Valdés consignó a las mujeres capturadas en Majana a la Casa de Beneficencia y a los hombres a la Junta de Fomento. Las obras públicas absorbieron una parte importante de la mano de obra emancipada. Tanto Vives como Ricafort los destinaron a los trabajos del Acueducto de Fernando VII. Durante el gobierno de Tacón se emplearon en el empedrado de calles, construcción de puentes y jardines, y en la edificación de la nueva cárcel. Aseguraba Domingo del Monte en un interrogatorio realizado por Madden que se levantaban «cárceles con el precio de la libertad de los negros emancipados» ${ }^{29}$.

Entre los particulares que se beneficiaban de las concesiones existía un grupo de viudas, de empleados del gobierno y de militares retirados, que los utilizaban en el servicio doméstico y los empleaban en diversos oficios en las ciudades. En efecto, tenemos noticias de emancipados cigarreros, aguadores, caleseros, panaderos, lavanderas o cocineras. Sabemos que se emplearon en los ferrocarriles de Güines, Cárdenas, Cienfuegos y Trinidad. Trabajaron también en los servicios de alumbrado de las ciudades; en 1845 la compañía de gas de La Habana recibió 50 como alumbradores de luz. Para incentivar la minería del cobre que entonces repuntaba en el Oriente cubano, se cedieron emancipados a diversas compañías ${ }^{30}$. Del mismo modo, con el fin de estimular

27 Galloti Mamigonian, 2009a: 236-237.

28 Real Orden de 13 de marzo de 1852 dispuso que se facilitasen al comándate del apostadero de La Habana los que necesitase, Rodríguez San Pedro, 1865, II: 600.

29 Madden, 1840: 103.

30 Defensa de la verdad y de los mineros de la isla de Cuba, 1839: 66. Madden, 1840: 124. 
el cultivo del algodón durante la escasez producida por la contienda civil en los Estados Unidos se entregaron a diversos plantadores en 1865, entre otros a Carlos Manuel de Céspedes para que los empleara en la Demajagua, donde poco después pronunció el grito de independencia ${ }^{31}$.

Inevitablemente, la consignación dio lugar a innumerables abusos y a un auténtico tráfico de emancipados. Los periodos se fueron renovando indefinidamente sin que su incorporación a la comunidad de los negros libres pareciera llegar nunca. Surgieron toda una serie de negocios que podían realizarse con estos negros y su consignación se convirtió en algo muy apetecido, porque podía proporcionar una renta suculenta a los consignatarios y mano de obra barata a los plantadores. Estos problemas pueden ilustrarse con ejemplos que arrojan luz sobre la vida del emancipado urbano, similar a la del esclavo de las poblaciones. El caso de Gabino saltó a la luz cuando en 1841 David Turnbull, el cónsul británico en La Habana y superintendente de africanos liberados, reclamó a las autoridades su inmediata puesta en libertad. Capturado a bordo del Fingal, la comisión mixta le había declarado emancipado en 1824 y había sido entregado a Luisa Apreu de Paz, que le obligaba a trabajar como aguador. Gabino entregaba a su «instructora» el jornal diario de un peso. Después de los cinco primeros años, su consignación se prolongó por otros cinco, y luego por cinco más. En esos años proporcionó a su consignataria 5.228 pesos $^{32}$. Ella había pagado por sus servicios 612 pesos. La muerte de su tutora no puso término a las penalidades de Gabino, que pasó a manos de su heredero. Consciente de la imposibilidad de hacer valer sus derechos, como algunos otros emancipados, Gabino acudió al cónsul en busca de protección. Tuvo éxito y obtuvo su carta de libertad. Pero pocos meses después, en noviembre de 1841, fue deportado a Ceuta, después de haber sido acusado de instigar un levantamiento de negros. Poco después moría en Cádiz.

No transcurrió mucho tiempo sin que se evidenciara que el disfrute de los derechos del hombre libre que jurídicamente se le habían reconocido al emancipado iba a ser difícil de alcanzar y que su suerte iba a ser similar a la de los esclavos, a los que de hecho se asimiló. Quienes han estudiado la esclavitud han resaltado las diferencias existentes entre la esclavitud en el medio urbano y el rural. Los esclavos de las poblaciones tenían más oportunidades de adqui-

31 Archivo Nacional de Cuba, La Habana (ANC), Gobierno Superior Civil, legajo 1581, exps. 41814-41829.

32 David Turnbull al príncipe de Angola, 21 de diciembre de 1841, AHN, Estado, legajo 8057, y Reclamación del plenipotenciario británico al secretario de Estado en favor de Gavino, 22 de marzo de 1842, Estado, legajo 8019, en Roldán de Montaud, 57 / 169-170 (Madrid, 1982): 598-599. Recientemente se ha abordado el caso de Gabino por Grandío Moráguez, 2008. 
rir la libertad, ya fuera por coartación o manumisión ${ }^{33}$. En las condiciones de reparto de emancipados se prohibía, según queda señalado, que los negros fuesen alejados de la ciudad y sus arrabales sin autorización del Gobierno. Turnbull aseguraba que esta regla había sido observada escrupulosamente hasta la llegada a Cuba del general Tacón en $1835^{34}$. Dado el carácter abolicionista del cónsul, el hecho de que hiciera distingos entre los capitanes generales parece sugerir que, efectivamente, desde entonces se produjo un empeoramiento de la situación de los emancipados.

Precisamente entonces comenzaron a exigirse entre seis y nueve onzas de oro (102 o 123 pesos) por consignación, cobradas en la Secretaría de Gobierno, una práctica que Madden denunció como contravención de las estipulaciones del Tratado ${ }^{35}$. Con anterioridad, según las condiciones de reparto, los consignatarios abonaban dos reales y medio por cada día que el emancipado hubiera permanecido en el depósito causando gastos el erario público, una cantidad insignificante. El particular que abonaba la importante suma de nueve onzas por una consignación (un bozal costaba entonces 20 o 23 onzas) consideraba al emancipado una propiedad que debía retribuirle el interés del dinero que había costado sin importar en absoluto su futuro.

Además de consignarse por sumas de consideración, desde la llegada de Tacón los emancipados comenzaron a entregarse a los plantadores del interior. La permanencia de los negros en la capital, si no era una garantía, les brindaba al menos alguna posibilidad de llegar a ser hombres libres; enviados a los ingenios, morían para la libertad ${ }^{36}$. Tacón no negaba que «la tranquilidad pública» le había obligado a colocar a los emancipados en las haciendas del campo. Adoptada la costumbre de consignar a los emancipados por sumas elevadas y de enviarlos a los ingenios azucareros, su condición se equiparó a la del esclavo rural. Perdía las ventajas del esclavo urbano y era absorbido en las dotaciones de esclavos de las fincas.

En cierto sentido, la situación del emancipado era peor que la del esclavo. De hecho, estaba privado de la protección y de los derechos que consuetudina-

33 Para el funcionamiento de la coartación, Madden, 1849: 133-144. Varella, 2010.

34 Turnbull, 1840: 162. También Madden aseguró que en época de Tacón se había realizado de forma escandalosa el tráfico con emancipados, Madden, 1849: 39.

35 Madden, 1840: 122. El gobierno español no escatimó esfuerzos para que fuera relevado, AHN, Estado, legajo 8022.

36 Nota del comisionado juez británico a Tacón, 9 de diciembre de 1834, y Nota de Villiers a Istúriz, 27 de mayo de 1836, AHN, Estado, legajo 8034. Comunicación de Tacón al secretario de Estado, 31 de agosto de 1836, AHN, Estado, legajo 8035. Pérez de la Riva, 1963: 262. 
riamente se reconocían al esclavo, entre otros, la coartación. Esta institución permitía al esclavo obtener la libertad pagando a su dueño el precio que valía en el mercado, pero quedaba fuera del alcance del emancipado. Cuenta el mencionado Del Monte que en cierta ocasión algunos emancipados habían intentado conseguir la libertad, ofreciendo por ella el precio que cualquier persona hubiera pagado para mantenerlos a su servicio, y que el gobierno se había negado ${ }^{37}$. Recientes estudios han mostrado cómo la coartación fue haciéndose cada vez más compleja y de difícil acceso para los esclavos, pero era, al fin, una posibilidad que el derecho reconocía. Tampoco podían los emancipados obtener la libertad mediante la manumisión del amo, ya que no estaban sujetos a la voluntad del consignatario sino a la del gobierno ${ }^{38}$. Sin discutir aquí la eficacia de la manumisión y la coartación como vías de ascenso de los esclavos a la libertad, se trataba de instituciones que el derecho esclavista reconocía a los esclavos de cuyos beneficios quedaban excluidos los emancipados.

Los emancipados no podían acudir tampoco a los procuradores síndicos de los ayuntamientos, que eran los encargados de velar por los derechos de los esclavos, de representarlos en los juicios y de instruir las causas por delitos contra sus personas desde 1789 . No podían presentarse ante el síndico para solicitar por su mediación un cambio de propietario, tal y como, en principio, podían hacer los esclavos. Aunque en la práctica la eficacia de estos preceptos fuera escasa, porque los funcionarios que administraban justicia eran ellos mismos propietarios de esclavos, al menos el ordenamiento jurídico establecía que los esclavos podían buscar protección en estas instituciones. Hasta 1856 no se dispuso que los síndicos fueran los defensores y representantes de los emancipados en los juicios de conciliación y verbales, y que los promotores fiscales y el fiscal lo fueran en los escritos seguidos ante los jueces y tribunales ordinarios ${ }^{39}$. Aun así, jamás se intentó defender el derecho del emancipado a la libertad después de los cinco años de aprendizaje y sus reivindicaciones parece que se limitaban a los casos de mal trato, según asegura Valiente.

EN TORNO A LOS ABUSOS Y SUS EFECTOS DEMOGRÁFICOS

Contra los emancipados se cometieron todo género de abusos. Uno de los más frecuentes era el que en Cuba se denominó plagio, del latín plagium o

37 Madden, 1840: 118.

38 Valiente, 1869: 14. Madden, 1840: 118.

39 Erénchun, 1858, II: 1444, Decreto de 27 de junio de 1856. 
venta de un hombre libre ${ }^{40}$. Consistía en dar por muerto a un emancipado cuando en una finca moría un esclavo. El emancipado ocupaba el lugar del esclavo muerto y se convertía en siervo para siempre. Bastaba con cambiar el nombre del negro al dar parte al cura y al capitán de partido. En ocasiones, no se esperaba siquiera la muerte de un esclavo para reemplazarlo por un emancipado. Se hacía pasar por muerto a este último ${ }^{41}$. A cambio de una remuneración, el juez rural y el párroco testificaban la muerte y estas falsas pruebas se enviaban a la Secretaría Política. Parece que llegó a darse el caso de haberse recibido en dicha oficina las partidas de defunción de negros que, si bien habían sido consignados, todavía no habían sido extraídos del depósito ni enviados a la finca en la que se decían fallecidos ${ }^{42}$. Ya en las condiciones de reparto de 1824 se había previsto esta eventualidad. En su artículo octavo se establecía una multa de 500 pesos para quienes vendiesen o se deshiciesen del emancipado dándolo por muerto o huido, además de las penas que las leyes fijaban para la venta de un hombre libre. En otros artículos se describían las diligencias que en caso de muerte o fuga debía adoptar el comisario de barrio, obligado a personarse con dos hombres buenos para certificar que se trataba del mismo negro y abrir las investigaciones necesarias hasta quedar convencido de ello; garantía irrisoria contra la voracidad de mano de obra de aquella agricultura esclavista.

No se dispone de demasiada información estadística que permita conocer el número de emancipados existentes en cada momento, los muertos y los que llegaron a obtener su plena libertad. Los contemporáneos reconocían que el desorden que desde un principio se había mantenido y el falseamiento de las cifras para encubrir abusos impedían esclarecer estas cuestiones. En cualquier caso, sí se tienen suficientes datos para intentar una estimación de las tasas de mortalidad, o de desaparecidos, para distintos momentos. En algunos periodos fueron extremadamente elevadas, lo que parece confirmar la existencia del mencionado plagio.

Hasta marzo de 1831 se habían capturado 15 buques y se había emancipado a 2.989 negros, de los que dos terceras partes eran varones. En dicha fecha, se daban por existentes 2.380 emancipados $^{43}$. Un sencillo cálculo permite fijar

40 Sobre el verdadero plagio o venta de hombres libres, véase Aparisi y Guijarro, 1888.

41 Madden, 1849: 39. Estorch, 1856: 16-19, para la descripción de los abusos por parte de uno de los vocales de la Junta Protectora de Emancipados. Sanromá, 1872: 21-22.

42 Figuera, 1866: 15.

43 Estado general que manifiesta el número de emancipados existentes de los 15 buques que desde 1824 hasta la fecha han sido apresados por otros de guerra ingleses, 12 de marzo de 1831, AHN, Estado, legajo 8033, exp. 2. 
la media anual de muertes (o desapariciones) hasta entonces en 3,30\%, algo mayor para los varones. Se trata de una cifra muy modesta comparada con las que se registran para periodos posteriores y con la que diversos autores han estimado para los esclavos. En fechas tan tempranas todavía los emancipados no habían comenzado a entregarse a los plantadores del interior y posiblemente residían en La Habana, según aseguraba Turnbull. No puede negarse, sin embargo, que la población emancipada no había sido diezmada todavía por la epidemia de cólera de 1833.

Disponemos de un estado de los emancipados existentes en 1841, que reproducimos en el cuadro II. En él se detalla el año de captura y el buque que había conducido a los negros que sobrevivían aquel año. A partir de dicha información y de otros datos dispersos en la correspondencia consultada, se puede estimar el número de emancipados desaparecidos o muertos en distintos periodos $^{44}$. Así, cuando en octubre de 1843 se inició el mando del general O’Donnell había 3.743 emancipados. Si se agregan los 734 aprehendidos desde junio de 1841 hasta dicha fecha y se deducen los 1.300 a los que el general Valdés concedió cartas de libertad (como se verá más adelante), en octubre debían existir 3.916 emancipados. La diferencia, apenas 170, sería el número de muertos o desaparecidos. Una cifra baja que corresponde al periodo de gobierno del general Valdés, a quien se atribuye un estricto cumplimiento de las estipulaciones de los tratados respecto a los emancipados y un control de los abusos más escandalosos.

Es interesante comparar esto con lo ocurrido poco después. Cuando O’Donnell llegó a La Habana, octubre de 1843, había 3.743 emancipados. Hasta febrero de 1848, cuando finalizó su mando, fueron capturados 229 y obtuvieron la libertad 459. A su partida sólo había 2.353 emancipados, es decir, habían desaparecido 1.163 , un 33\%, lo que arrojaría para los cuatro años y medio de su mando un 6,61\% anual de muertos o desaparecidos. Al iniciar el mando Federico Roncali, en febrero de 1848, existían 2.353 emancipados. A la llegada del general Concha, en noviembre de 1850, se suponía que había 2.138 emancipados $^{45}$. Entre una y otra fecha se habían apresado 387 negros y concedido cartas de libertad a 222, luego en noviembre debían existir 2.518 y no 2.138 , lo que arrojaría una media de desaparecidos o muertos de $6,03 \%$ para el periodo de su mando. Un ejemplo más: en 1857 se capturaron siete expediciones y se emancipó a 2.111 esclavos. Transcurridos cinco años, en 1862

44 Para las argumentaciones que siguen, Roldán de Montaud, 57 / 169-170 (Madrid, 1982): 582-589.

45 Gutiérrez de la Concha al secretario de Estado, 9 de junio de 1851, AHN, Estado, legajo 8044 . 


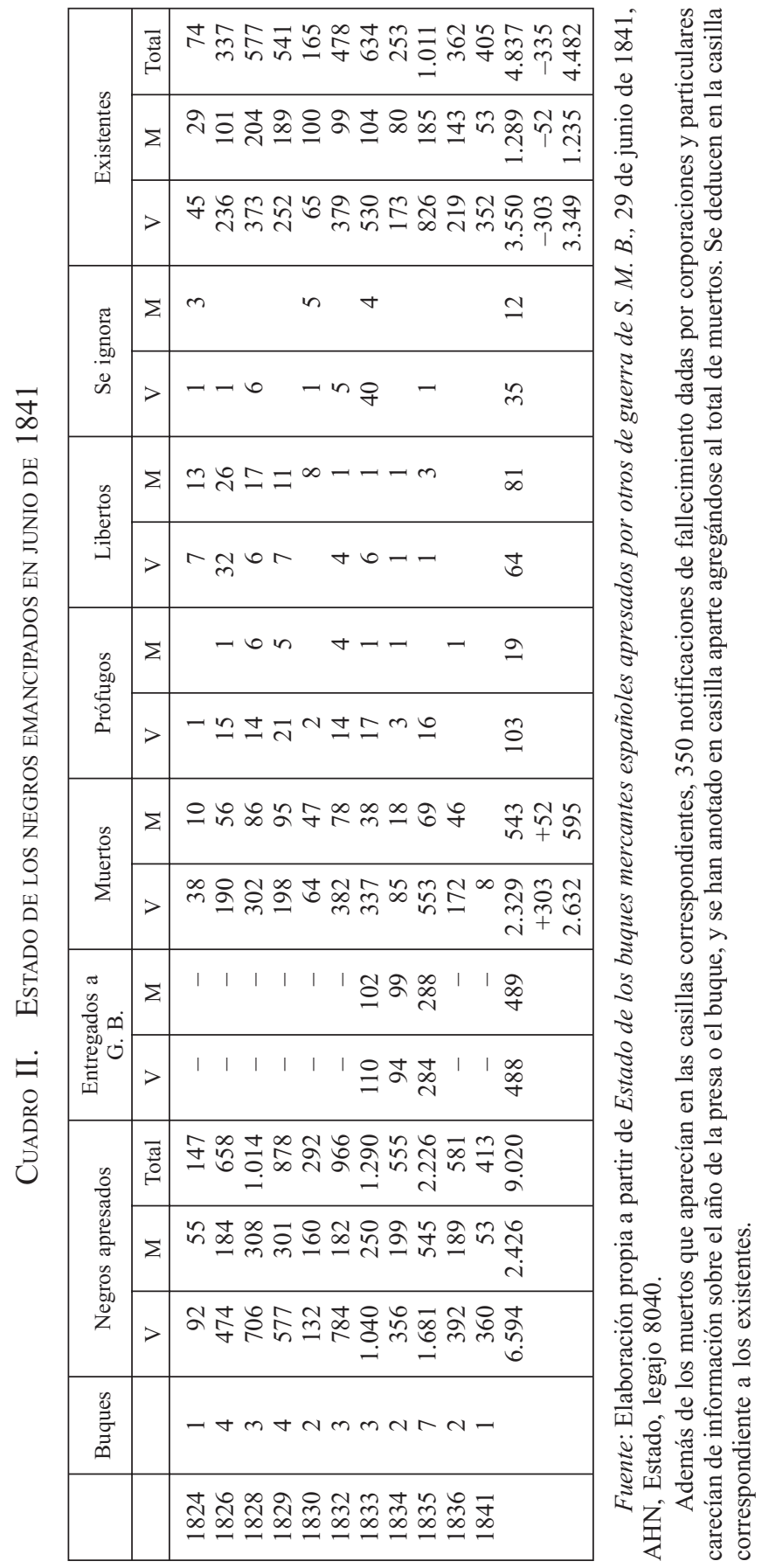


sólo quedaban 734 . Había desaparecido o fallecido el $65 \%$, es decir, un promedio anual del $10,87 \%{ }^{46}$.

Se trata de cifras superiores a las tasas de mortalidad estimadas para los esclavos del azúcar. En efecto, Humboldt calculó que era del 8\%, los comisionados británicos para los adultos rurales entre un 2 y un 5\% y Moreno Fraginals la ha fijado en un $6,3 \%{ }^{47}$. La conclusión era ya evidente para algunos contemporáneos: «Verdad es que el guarismo de su mortalidad es exorbitante y revela o un mal trato o una serie de delitos sobre los cuales no se extiende con suficiente energía la mano de la justicia» ${ }^{48}$.

Las tasas de natalidad no guardaban tampoco relación con las que se han estimado para los esclavos. Según los datos del presupuesto del ramo para el ejercicio 1856-1857, habían nacido en Cuba tres varones y ocho mujeres; en 1858, sólo tres y siete respectivamente. Como en Brasil, heredaban el status ambiguo de sus padres en vez de ser considerados libres ${ }^{49}$. En abril de 1861 los funcionarios de Madrid llamaban la atención de las autoridades cubanas sobre el hecho de que en el último presupuesto sólo aparecieran 12 menores criollos de ambos sexos. El Cuadro estadístico de 1862 computó 21 varones y 18 mujeres menores de un año ${ }^{50}$, lo cual representaba una tasa de natalidad (existían 6.650 emancipados) de 5,86\%. Moreno Fraginals estimó tasas del 19\% entre $1835-1841$ y del 28\% entre 1856-1860, tras el inicio de una política de reproducción estimulada por el aumento del precio de los esclavos ${ }^{51}$. Sin disposiciones que aseguraran el cumplimiento de la obligación que tenían los consignatarios de dar cuenta de los nacimientos acaecidos, los nacidos de las negras emancipadas fueron sumidos en la esclavitud.

El censo de población del año 1861 fue el único de los censos cubanos en el que se recogieron datos relativos a los emancipados, fijando su número en $6.650^{52}$. En la parte oriental de Cuba, alejada de la sede del tribunal mixto y de las autoridades encargadas de su distribución, la presencia de emancipados fue insignificante y se concentró en la jurisdicción de Santiago de Cuba, con un $2,82 \%$ del total de la isla. El trabajo en las minas de cobre de Santiago del Prado seguramente explica esta presencia. La única jurisdicción de la zona orien-

46 Comunicación de Dulce fechada en diciembre de 1862, AHN, Ultramar, legajo 4666.

47 Humboldt, 1856: 203. La cifra de los comisionados en Kiple, 1976: 53. Moreno Fraginals, 1978, II: 88 .

48 Figuera, 1866: 14.

49 Gallotti Mamigonian, 2009: 237.

50 Presupuesto del ramo de emancipados de 1856-57-58, BN, ms. 13853. Gutiérrez de la Concha, 1861: 16. Cuadro estadístico, 1862.

51 Moreno Fraginals, 1978, II: 88.

52 Cuadro estadístico, 1862. Roldán de Montaud, 57 / 169-170 (Madrid, 1882): 589-592. 
tal con elevado número de emancipados era Puerto Príncipe, con un $8,39 \%$ del total. Con motivo de la entrega del mando a Serrano en 1859, el general Concha relataba la captura de 448 bozales por el vapor de guerra Blasco de Garay y su conducción a Puerto Príncipe, donde dispuso que se distribuyeran en su totalidad en beneficio de los propietarios ${ }^{53}$.

La mayor parte de los emancipados se encontraba en el departamento occidental. En la jurisdicción de La Habana había un 35,84\% del total. Había importantes porcentajes en Sagua, Colón, Santiago de las Vegas y Cárdenas, $5,17,4,99,4,70$ y 4,24 y respectivamente, todas ellas zonas productoras de azúcar. En general, estaban afincados en las áreas de intensa actividad económica y donde existía gran número de esclavos.

\section{LA PRESIÓN ABOLICIONISTA BRITÁNICA}

A los negros emancipados les resultó muy difícil llegar a obtener la preciada carta de libertad, el documento que les garantizaba su condición civil de hombres libres. La resistencia a declarar a los emancipados exentos de la tutela del gobierno fue constante. No cabe duda de que cuando el gobierno de Madrid o las autoridades coloniales se mostraron más dispuestos a conceder cartas de libertad fue siempre resultado de la presión abolicionista británica, que utilizó constantemente como ariete la libertad de los emancipados. Aun cuando el garante de la libertad de los negros fuera el gobierno español, en virtud de los tratados el gobierno británico tenía derecho a exigir el cumplimiento de esa garantía. Semejante situación abría un resquicio que le permitía inmiscuirse en los asuntos internos de Cuba relacionados con la esclavitud.

Cuando las autoridades inglesas acusaban a las cubanas de permitir el contrabando de africanos, invariablemente el gobierno español se excusaba asegurando que se intentaba por todos los medios posibles poner fin a tan inicuo comercio. El grupo emancipado resultaba un elemento real y objetivo de presión. Era más fácil presionar y exigir el cumplimiento de las obligaciones concretas respecto a este grupo, fruto de esa trata clandestina, que sobre las «intenciones» de un gobierno. Si Gran Bretaña lograba arrancar de la esclavitud a los emancipados que no eran otra cosa que esclavos ilegalmente introducidos, podría luego hacer extensiva esta medida a los que no habían sido descubiertos en el momento de desembarco pero que arribaban por millares a la isla.

53 Gutiérrez de la Concha, 1861: 17. 
De los 6.554 hombres y 2.426 mujeres emancipados hasta el 29 de junio de 1841, a pesar de que habían transcurrido quince años desde el apresamiento de los primeros, sólo habían obtenido sus cartas de libertad 64 hombres y 81 mujeres. Como era de suponer, hubo mayor tendencia a liberar a las mujeres y a los más antiguos. En efecto, de los 64 varones, 52 habían sido capturados antes de 1829; el resto, antes de 1835. Dado que el promedio de vida de un esclavo adulto en un ingenio era de unos quince años, los emancipados que llegaron a disfrutar de su libertad eran, sin duda, los que resultaban ya poco hábiles para el trabajo. En cualquier caso, la entrega de la carta de libertad no era garantía de que los negros en cuestión llegaran a disfrutar de una libertad real y efectiva. En efecto, cuando el general Concha dispuso en 1854 que se renovasen todas las consignaciones de los emancipados para saber cuántos existían, resultó que se pedía la renovación de negros que ya habían obtenido su carta de libertad, lo que permite sospechar que o no había sido entregada al verdadero negro o quizá a ninguno y que el agraciado probablemente se veía reducido a esclavitud ${ }^{54}$.

En los primeros años cuarenta arreció la presión abolicionista británica. El 3 de noviembre de 1840 llegó a La Habana David Turnbull. Como Madden, era miembro de la British and Foreign Anti-Slavery Society y había vertido sus posiciones abolicionistas en su reciente libro Travels in the West. Con él en Cuba, la cuestión de los emancipados se iba a convertir en uno de los mayores puntos de fricción en la disputa que Gran Bretaña y España mantenían sobre el tráfico de esclavos. A propuesta del cónsul, en diciembre de aquel año Inglaterra trató de imponer la firma de un convenio para emancipar a los esclavos que se habían introducido ilegalmente desde $1820^{55}$. Dado el promedio de vida de los esclavos, la medida equivalía llanamente a abolir la esclavitud. Aunque España se resistió, Inglaterra logró un mayor compromiso en el cumplimiento de las estipulaciones de los tratados.

En mayo de 1841 desembarcó en La Habana el general Valdés con instrucciones de castigar severamente el tráfico. Ese mismo mes, Inglaterra sugería a España que los emancipados fueran presentados ante la comisión mixta con objeto de averiguar su situación y saber si preferían ser trasladados a una colo-

54 Gutiérrez de la Concha al secretario de Estado, 12 de junio de 1856, BN, ms. 13853, fols. 164-165.

55 Proyecto de convenio sobre la emancipación de esclavos, 17 de diciembre de 1840. AHN, Estado, legajo 8040, exp. 7. Se proponía aumentar las atribuciones de la comisión mixta para declarar libres a los esclavos que se sospechara habían sido ilegalmente introducidos. Turnbull, 1840: 342-348.

56 Legación de Gran Bretaña al secretario de Estado, 15 de abril de 1840 y 31 de mayo de 1840, AHN, Estado, legajo 8035. El 15 de abril 1840 ya se había realizado una petición similar. 
nia británica ${ }^{56}$. Inglaterra había abolido la esclavitud en sus Antillas en 1833 y la transición del trabajo esclavo al asalariado estaba produciendo desajustes con la consiguiente disminución de la producción. Para paliar el problema, se habían llevado «aprendices» desde los enclaves ingleses en África y trasladado a miles de negros emancipados por la comisión mixta de Sierra Leona ${ }^{57}$. Con la excusa de garantizar su libertad, se trataba también de atraer a los emancipados cubanos.

La propuesta era inaceptable para España porque equivalía a admitir que una autoridad extranjera examinase la condición de los negros emancipados en virtud del Tratado de 1817 que estipulaba su entrega al gobierno donde residiera la Comisión. Si en los primeros años las autoridades españolas habían procurado deshacerse de los emancipados, ahora no parecían dispuestas a prescindir de aquellos negros. Por lo demás, estaban convencidas de que si se transigía en el caso de los emancipados sería imposible resistirse a la pesquisa sobre los esclavos. Valdés estaba decidido a poner término a la trata, pero también a defender la institución esclavista que era imprescindible para el mantenimiento de la colonia ${ }^{58}$.

Dispuesto, no obstante, a suprimir los motivos de queja y a evitar nuevas exigencias, Valdés se comprometió a entregar las cartas de libertad a los emancipados en un plazo de cinco años desde enero de 1842, según fueran venciendo las consignaciones ${ }^{59}$, lo que no le impidió poner coto a la propaganda emancipadora de Turnbull entre los esclavos y libres de color expulsándolo de la isla. Entre enero de 1842 y septiembre de 1843, cuando abandonó el mando, había entregado $1.300 \operatorname{cartas}^{60}$. Los comisionados británicos reconocieron que se estaban concediendo las cartas de libertad y por primera vez en Londres se celebraba la conducta de un capitán general en cuanto al cumplimiento de los tratados ${ }^{61}$.

Para tranquilizar a los plantadores, que estaban convencidos de que España se vería arrastrada a abolir la esclavitud, y evitar que se fortaleciese entre ellos la corriente anexionista hacia Estados Unidos, tras la caída de Espartero, en octubre de 1843 el gobierno cambió de política y envió a Cuba al general Leopoldo O'Donnell. Poco después de su llegada se produjo una insurrección de

57 Desde 1820 hasta el 1 de enero de 1839 la Comisión de Sierra Leona emancipó a 55.359 negros, Madden, 1849: 40. Véase también Bethell, 80 (1966): 89. Arnalte, X / 18-19 (Madrid, 1996): 65-79. Sobre el traslado de emancipados de Sierra Leona, Shlomowitz, 1989.

58 Valdés al secretario de Estado, 31 de mayo de 1841, AHN, Estado, legajo 8035.

59 Valdés al secretario de Estado, 31 de julio de 1841, AHN, Estado, legajo 8040.

60 Valdés al secretario de Estado, 30 de abril de 1842, AHN, Ultramar, legajo 4039.

61 Pezuela, 1878, IV: 360. Franco, 1980: 374. 
esclavos, la Conspiración de la Escalera, brutalmente reprimida por el general $^{62}$. Cientos de esclavos murieron asesinados. Como se consideraba que los libres de color estaban implicados y que la liberación de los emancipados había contribuido a aumentar la inquietud entre los esclavos, en marzo de 1844 O’Donnell suspendió la concesión de cartas de libertad y la entrega de las listas de los emancipados liberados que Valdés remitía regularmente a los comisionados ingleses. En abril, comunicaba al Gobierno las medidas que debían adoptarse para garantizar el orden: se expulsaría inmediatamente a los negros y mulatos de procedencia extranjera; concluidos los procesos incoados, se procedería a la expulsión lenta, sucesiva y prudente no sólo de los implicados sino de todos los negros y mulatos libres. También sería deportada la multitud de emancipados a quienes su antecesor había concedido cartas de libertad dejándoles permanecer en la isla, donde «el derecho que en medio de las negradas se les hizo conocer que tenían a su libertad, había sido tan funesto» ${ }^{63}$. El gobierno de Madrid aceptó la expulsión de los implicados y que fueran enviados a Fernando Poo los negros que voluntariamente y a su costa lo deseasen.

Como la suspensión de la entrega de cartas de libertad podía producir reclamaciones por parte de Inglaterra, en septiembre se reanudó de forma limitada, haciéndose entrega de algunos de los agraciados a las autoridades británicas, algo a lo que se habían negado sistemáticamente los capitanes generales desde 1836. Lo cierto es que en el nuevo contexto de recrudecimiento de la tensión racial, las autoridades recurrieron a tal procedimiento para deshacerse de los elementos más incómodos de un grupo estimado socialmente peligroso. En 1845 se entregaron a los ingleses 214 emancipados, prácticamente los que se liberaron aquel año; al año siguiente, 132.

Desde 1845 a 1851 el cónsul inglés recibió 657 emancipados de los 788 liberados en el periodo. Vencidos los temores inmediatos a la Escalera, se fue reduciendo tanto la entrega de cartas como el número de negros cedidos a las autoridades británicas ${ }^{64}$. La política y el interés del país, aseguraba O’Donnell, exigían que hubiera «sobriedad en la entrega de las cartas». De concederse la libertad a todos, tendrían que ser entregados a los ingleses o permitir su permanencia en la isla como libres, lo cual era nocivo para la tranquilidad y en

62 Hernández Sánchez Barba, XIV (Sevilla, 1957): 241-329. Paquette, 1988.

63 O'Donnell al secretario de Estado, 30 de marzo y 26 de abril de 1844, AHN, Ultramar, legajo 4620, exp. 33, y 15 de abril de 1844, Estado, legajo 8039. Roldán de Montaud, 57 / 169-170 (Madrid, 1982): 613-618.

64 Lista de los esclavos de Cuba que han recibido cartas de libertad desde 1845 a 1851, enviada al plenipotenciario británico el 26 de marzo de 1852, AHN, Estado, legajo 8037, y AHN, Ultramar, legajo 4046. 
ambos casos se aumentaría el «vacío sensible de brazos» ${ }^{65}$. De modo que quedó abandonado el plan de Valdés, que en dos años había liberado a 1.300 negros.

Las quejas británicas prosiguieron. Lord Palmerston aprovechó el desconcierto que produjeron las expediciones anexionistas organizadas en los Estados Unidos para proponer, a finales de 1850, un nuevo convenio de pesquisa. También en aquellos momentos se ejercía una presión similar en Brasil ${ }^{66}$. España se negó a aceptarlo alegando que según las leyes internas quedaba prohibido molestar a los propietarios por motivo de la procedencia de sus esclavos $^{67}$. En 1852 las quejas arreciaron. Se exigía el cumplimiento de la promesa de Valdés, la entrega semestral de los estados de los emancipados prevista en el tratado de 1835 y que se permitiera al juez comisionado británico acceder a los registros de emancipados. Con la excusa de proteger a los emancipados, los británicos invocaban principios abolicionistas que amenazaban la estabilidad del sistema esclavista.

A la vista de las pretensiones, el secretario de Estado explicaba al capitán general que de accederse se pondrían al descubierto los abusos. Por ello era necesario «o que desaparezca el abuso de que los emancipados sean esclavos en realidad o que los estados se entreguen de tal manera que no resulte en descubierto la autoridad de la isla». Y agregaba: «Vale más la pena concluir con el abuso por nosotros mismos y evitar los escándalos que produciría el descubrimiento. De lo contrario, si se ha de sacar de los emancipados el partido que exigen las necesidades de la isla y que sacan los mismos ingleses en sus colonias, se deberá seguir el sistema de evasivas que se ha seguido hasta ahora ${ }^{68}$.

El gobierno británico estaba convencido de que los tratados contra el tráfico no dejarían de burlarse mientras persistiera la inmunidad de los ingenios y no se realizara un registro de los esclavos existentes. No tardaron en presentarse las circunstancias favorables para presionar al gobierno español. En efecto, en breve era elegido presidente de los Estados Unidos Franklin Pierce, conocido por su orientación marcadamente expansionista. El hecho movilizó a los anexionistas que proyectaban una gran expedición dirigida por el general Quitman. Ante la amenaza, la ayuda de Inglaterra se tornaba más necesaria

65 O'Donnell al secretario de Estado, noviembre de 1846, AHN, Estado, legajo 8040.

66 Gallotti Mamigonian, 2009a: 240.

67 Legación británica en España al marqués de Pidal, 6 de octubre de 1850, AHN, Estado, legajo 8040.

68 Despacho del secretario de Estado a Cañedo, 14 de septiembre de 1852, Informe del Consejo de Ultramar acerca del Expediente de emancipados en la isla de Cuba, 11 de marzo de 1853, y Real Orden de 31 de marzo de 1853, AHN, Estado, legajo 8046. 
que nunca, pero España debía hacer concesiones. De modo que por real orden de 31 de marzo de 1853 se mandó poner en libertad, antes de que finalizara el año, a todos los negros emancipados por la comisión mixta de La Habana con arreglo al tratado de 1817. En cuanto a los posteriores a 1835, se daría la libertad a los que hubieran cumplido cinco años de consignación ${ }^{69}$. La inclusión de los negros que habían sido emancipados por disposición de las autoridades españolas mostraba la necesidad de apoyo en un momento extremadamente grave para la soberanía española en Cuba. La decisión se puso de inmediato en conocimiento del gobierno británico.

Para ejecutar la nueva política se enviaba a Cuba al general Juan Manuel de la Pezuela en diciembre de 1853. No tardaba en adoptar medidas que sembraron el pánico entre hacendados y negreros. El 20 de diciembre dispuso que se diera la libertad a los negros emancipados más antiguos que existían en el depósito, procedentes de las expediciones apresadas antes de 1835; pero mientras permanecieran en la isla quedarían bajo la tutela del gobierno y contratarían sus servicios como jornaleros libres con su patrono o con el que más le acomodase. Los patronos que tuvieran derechos sobre los negros que les hubieran sido consignados serían indemnizados ${ }^{70}$. El 1 de enero de 1854 publicaba una ordenanza en la que regulaba ampliamente la situación de los emancipados. Los negros conocidos con el nombre de emancipados, rezaba el artículo primero, eran libres todos. Los que llevasen cinco años en poder de la autoridad y tuvieran 16 obtendrían sus cartas de libertad, contratarían su trabajo durante un año renovable y tendrían derecho a un jornal de seis pesos mensuales los varones y cuatro las mujeres, tres cuartas partes para el liberto y una para el fondo de emancipados. El jornal de los que no llevasen cinco años sería administrado por la Junta Protectora de Emancipados ${ }^{71}$. La ordenanza fue el primero de los actos de Pezuela que alarmó a plantadores y esclavistas por los términos en que estaba redactada, pese a que no garantizaba la libertad de los emancipados.

Hasta entonces se habían capturado 11.248 negros, 8.769 por los cruceros británicos y 2.479 por las autoridades cubanas. Se habían enviado a Trinidad 997 en los años treinta y otros 657 en los cuarenta. Habían recibido sus cartas

69 Informe del Consejo de Ultramar acerca del expediente de emancipados en la isla de Cuba, 11 de marzo de 1853, y Real Orden de 31 de marzo de 1853, AHN, Estado, legajo 8046. Nota del conde de Alcoy, 4 de marzo de 1853, AHN, Ultramar, 4666. Murray, 1980: 292-293.

70 Biblioteca Nacional (Madrid) manuscrito 13853, fols. 77-78. Gutiérrez de la Concha, 1861: 8 .

71 Ordenanza de Emancipados de 1 de enero de 1854, BN. ms. 13853, fols. 79-82. 
de libertad unos 2.063, la mayor parte en época de Valdés. Se suponía que existían 2.098. Los restantes se daban por muertos o desaparecidos. Sin embargo, cuando Pezuela convocó mediante la Gaceta a los consignatarios sólo se presentaron 900 emancipados, pese a que el reglamento preveía multas que se cobrarían ejecutivamente ${ }^{72}$. De ellos, fueron muy pocos los que llegaron a obtener su certificado de libertad y a escoger a su propio patrono, entre otras cosas porque Pezuela fue relevado en el mes de septiembre ${ }^{73}$. Con todo, los esfuerzos realizados entonces fueron apreciados por Gran Bretaña, como muestra la correspondencia de Clarendon ${ }^{74}$. Observadores destacados por su posición crítica con la administración española, como Porfirio Valiente, reconocieron también que Pezuela había intentado hacer todo lo posible para dar la libertad completa a los emancipados ${ }^{75}$.

El 3 de mayo Pezuela dictó un bando facultando a las autoridades a entrar en las propiedades para comprobar la identidad de los negros. Anunció también la creación de un registro de esclavos y la declaración de libertad de todos los que no figurasen en él, como instrumento para hacer eficaz la represión del tráfico. Ante semejantes proyectos, comenzaron a difundirse rumores de que deseaba «africanizar» la isla y de que Gran Bretaña y España habían acordado poner fin a la esclavitud ${ }^{76}$. El temor a que en breve se decretara la abolición produjo un crecimiento de la tendencia anexionista. Para restablecer la confianza, Pezuela fue sustituido por Concha, con el inmediato abandono de la política antiesclavista inspirada por Gran Bretaña. Lo cierto es que una vez superado el peligro de una intervención en la isla, apoyada por el gobierno federal, no había ya motivo para seguir complaciendo a Gran Bretaña.

Concha derogó el bando de mayo y abandonó el registro de esclavos. Sustituyó la ordenanza de emancipados de su predecesor, que tanto desagrado había suscitado entre plantadores y traficantes, por una nueva, que remitió a Madrid en el mes de diciembre ${ }^{77}$. En ella, tras un periodo de aprendizaje de cinco años, el emancipado quedaba sujeto a un régimen de colonato semejante al que se aplicaba a chinos o yucatecos mientras permaneciera en la isla. Por los emancipados aprendices varones, según fueran mayores o menores de 15 años,

72 Estado de los emancipados aprehendidos por cruceros ingleses y por las autoridades subalternas de la isla, 6 de febrero de 1854, AHN, Estado, legajo 8046.

73 BN, ms. 13853, fols. 97-98. Valiente, 1869: 13; Estorch, 1856: 15. Roldán de Montaud, 57 / 169-170 (Madrid, 1982): 624-627.

74 Estorch, 1856: 138-139.

75 Valiente, 1869: 13.

76 Urban, 37 / 1 (Durham, 1957): 29-45.

77 Durante su primer mandato también había prestado atención al ramo de emancipados, Gutiérrez de la Concha, 1861: 5. 
se abonaban seis y cinco pesos; cinco y cuatro por las mujeres que percibiría la Junta de Emancipados. Los emancipados ladinos o colonos recibirían un salario de ocho pesos los varones y seis las mujeres. La tercera parte de dicha cantidad ingresaría en la Junta de Emancipados, encargada de velar por el cumplimiento de la ordenanza. En realidad, no distaba tanto de la de su predecesor.

En 1854 el jornal de un negro variaba entre 20 y 25 pesos mensuales. Según los datos aportados por Aimes, entre 1855 y 1860 el precio de un esclavo en el mercado oscilaba entre 1.250 y 1.500 pesos $^{78}$. De modo que el emancipado representaba una mano de obra comparativamente muy barata. Con los emancipados se estaba ensayando el tránsito del trabajo esclavo a otro tipo de trabajo forzado en un momento de acuciante escasez y carestía de la mano de obra $^{79}$. Su situación se estaba asemejando a la de los colonos chinos, yucatecos e incluso a la de aprendices africanos. A pesar de la oposición británica, la Ordenanza de Concha fue aprobada en enero de 1855 y estuvo en vigor hasta $1865^{80}$. Sólo entonces, cuando se planteó seriamente la necesidad de ir hacia una abolición gradual de la esclavitud, volvió el gobierno de Madrid a ocuparse nuevamente de la cuestión de los emancipados.

\section{LA DÉCADA DE LOS SESENTA Y LA EXTINCIÓN DEL GRUPO}

Poco a poco fueron apareciendo signos de cambio. El anexionismo dio paso al predominio de posiciones reformistas entre los criollos, con la condena del tráfico de esclavos y la búsqueda de una solución gradual al problema de la esclavitud $^{81}$. Era evidente que mientras existiera el sistema servil sería difícil dignificar el trabajo agrícola y todo intento de asentar colonos blancos libres, en el que no pocos cifraban la solución al problema social, fracasarían. Por otra parte, el giro de los acontecimientos en los Estados Unidos fue determinante en la adopción de posiciones favorables a la desaparición definitiva del tráfico en los círculos gubernamentales de Madrid. En abril de 1861 había es-

78 Aimes, 1967: 268.

79 Véase, por ejemplo, Piqueras, 2009.

80 Rodríguez San Pedro, 1865, II: 600-605. En enero de 1855 se aprobó la ordenanza de Concha, exceptuando lo relativo al manejo de los fondos de emancipados. Hasta entonces habían sido gestionados por la Secretaría Política directamente y luego mediante una Junta de Emancipados. En 1855 se dispuso que los fondos ingresasen en el Tesoro público y sus presupuestos formaran parte del general del Estado en la Isla. Durante varios años Concha resistió aquella disposición, reiterada el 23 de septiembre de 1858. Poco después, la real orden de 12 de julio de 1860 prohibió la consignación gratuita. Roldán de Montaud, 57 / 169-170 (Madrid, 1982): 600-606. 
tallado la guerra y poco después Lincoln firmó un tratado reconociendo a los cruceros británicos el derecho de visita. El tráfico de esclavos desarrollado ampliamente bajo bandera norteamericana quedaba sentenciado. Desde aquel momento, el gobierno español no podía ya resistir las presiones para poner fin a la trata, pues si el norte abolicionista triunfaba en la contienda civil, los Estados Unidos utilizarían la cuestión de la esclavitud como pretexto para intervenir en los asuntos internos de Cuba.

En una sociedad en la que la mano de obra esclava estaba llamada a transformarse en un sector asalariado campesino, no tenía sentido seguir reteniendo en esclavitud a un grupo de condición libre, que si se había visto reducido a aquélla había sido precisamente por el potencial riesgo de que actuara como disolvente del sistema. En el momento en que se planteaba la lenta disolución de la esclavitud parecía oportuno comenzar por los emancipados, auténticos «esclavos del gobierno». Entre los proyectos de abolición gradual nacidos durante aquellos años no faltaron los que, en efecto, proponían como fase preliminar la liberación total de los emancipados ${ }^{82}$.

De modo que a finales de 1862, tras una consulta al Consejo de Estado, se dictaron disposiciones para poner término al problema de los emancipados. La real orden del 12 de diciembre mandó dividir a los emancipados que hubieran cumplido su primera consignación en tres series, que recibirían la libertad ese año y los dos siguientes ${ }^{83}$. Después irían obteniéndola los que en lo sucesivo fueran cumpliendo los cinco años, «a cuyo período quedaría inalterablemente reducido el plazo de consignación». Pero, una vez más, se restringía el alcance de la libertad ofrecida, pues se encomendaba al gobernador general que los negros quedaran sometidos a la ordenanza de colonos. En todo caso, la oposición de los plantadores y la escasez de mano de obra se concitaron contra la aplicación de la medida y las quejas de los cónsules británicos sobre el incumplimiento de los compromisos asumidos prosiguieron.

Concluida la guerra en los Estados Unidos llegó el momento de acabar con el tráfico. Era evidente que nadie creería que el gobierno se proponía sinceramente poner fin a la trata si continuaba aprovechándose indefinidamente de sus resultados. Había, pues, que convencer a propios y extraños — indicaba el

81 Corwin, 1967: 134.

82 López de Letona, 1865: 21.

83 Consulta a la Sección de Ultramar del Consejo de Estado, 14 de noviembre de 1862, AHN, Ultramar, legajo 4666. Concesión de carta de libertad a los emancipados de la isla de Cuba, Archivo del Consejo de Estado, Madrid (ACE), U-082-025, dictamen 14905. Rodríguez San Pedro, 1865, II: 606-607, real orden de 12 de diciembre de 1862 dictando reglas para la concesión de cartas de libertad. 
ministro de Ultramar, Antonio Cánovas del Castillo- de que el Gobierno estaba decidido a preparar de una manera pacífica la solución al problema de la esclavitud. Con dicho propósito, el 10 de agosto de 1865, el Consejo de Estado había aprobado un nuevo reglamento de emancipados que se ajustaba más al espíritu de los tratados suscritos con Gran Bretaña que el vigente de 1855. En él se reforzaban las garantías para evitar los abusos más frecuentes. Entre otras cosas, se remitiría a la Real Audiencia un listado de los emancipados y otro de los consignatarios. El fiscal de la Audiencia quedaba facultado para inspeccionar el depósito de emancipados cuando lo estimase oportuno ${ }^{84}$. En definitiva, se fiscalizaba la gestión discrecional que el capitán general había disfrutado hasta entonces. Por otra parte, desaparecía la figura del emancipado colono. Los nombres de los emancipados que cumplieran cinco años de consignación se publicarían en la Gaceta y desde entonces serían considerados como los demás libres de su raza.

El general Dulce decidió no aplicar la nueva ordenanza. Insistía en que cinco años eran un periodo insuficiente para el aprendizaje del negro, que por naturaleza era «indolente y perezoso» y «pasto de los tribunales de justicia o inquilino de los presidios». Lo cierto es que Dulce no ocultó su contrariedad por la inspección concedida a la Real Audiencia, que interpretaba como una desconfianza hacia el gobernador y que rechazaba en nombre de todos sus antecesores. Por otra parte, en aquella época la mayoría de los emancipados estaban en las fincas y el general era consciente de lo difícil que resultaría oponerse a las presiones de los plantadores cuyos intereses contrariaba $^{85}$.

La respuesta de Madrid no se hizo esperar. No se forzó el cumplimiento de la nueva ordenanza porque, dispuesto a poner fin al tráfico, el gobierno de la Unión Liberal decidió dar una solución radical y definitiva a uno de sus efectos: la existencia de los emancipados. La real orden de 28 de octubre de 1865 dispuso que los 105 negros apresados en septiembre en un punto denominado el Gato, en el límite de las jurisdicciones de San Cristóbal y Pinar del Río, fueran transportados a expensas del gobierno a Fernando Poo (cuadro I). Quedarían enteramente libres si deseaban permanecer allí o enviados a otro punto de la costa africana si así lo preferían. Se procedería del mismo modo con todos los negros aprehendidos en el futuro tan pronto como fueran declarados eman-

84 Reglamento para el régimen de emancipados, ACE, U-034-011, 1864, dictamen 18831. El texto quedó aprobado el 10 de agosto de 1865, AHN, Ultramar, 4666.

85 Sobre la actitud de Dulce ante la nueva ordenanza, Roldán de Montaud, 57 / 169-170 (Madrid, 1982): 633-634. 
$\operatorname{cipados}^{86}$. En cuanto a los existentes, ingresarían en el depósito cuando concluyera su consignación y el gobierno proveería todo lo necesario para su subsistencia y remuneración, ocupándolos en obras públicas mientras permanecieran en esa situación. Podría dejar en entera libertad y en las mismas condiciones que los demás libres de su clase a los que ingresasen en el depósito y hubieran cumplido cinco años de consignación. Como en el futuro no habría más consignaciones, quedaba revocada la facultad concedida a los gobernadores superiores civiles. Este «importantísimo decreto sobre emancipados» era, según la Revista Hispano-Americana, «el principio del fin» ${ }^{87}$. Ponía término al problema emancipado y a los abusos de cara al futuro. En todo caso, con posterioridad sólo se registró un nuevo apresamiento de bozales en las costas cubanas.

Preocupado por no privar de brazos a los plantadores durante la zafra, una vez más, el general Dulce hizo caso omiso de las disposiciones del gobierno. Finalmente, cedió: el 4 de marzo de 1866 dispuso que los emancipados pertenecientes a las 33 expediciones más antiguas fueran presentados en el depósito a fin de entregarles gradualmente su carta de libertad ${ }^{88}$. Desde noviembre de 1865 hasta mayo de 1866 Dulce extendió 421 cartas a los 6.650 emancipados existentes. Valiente reconocía que finalmente el gobierno había prescrito de manera enérgica la puesta en libertad de los emancipados y que por tal motivo se produjeron desacuerdos entre el Ministerio y los sucesivos capitanes generales. Aunque remoloneando, Dulce había concedido cartas de libertad, pero muy pronto las cosas habían vuelto a su estado acostumbrado y, sometido a la presión de los plantadores, abandonó la concesión. De ser cierta la afirmación de Valiente, esta conducta de Dulce condujo a su relevo en mayo de $1866^{89}$. Durante los años siguientes los sucesivos gobernadores concedieron cartas de libertad a un ritmo extremadamente lento y continuaron consignando emancipados, contraviniendo la ordenanza de $1865^{90}$.

86 Se quería resolver el problema de mano de obra que planteaba la ocupación de la colonia española del Golfo de Guinea. Desde 1860 diversas reales órdenes habían dispuesto el envío de emancipados, sin que las autoridades de Cuba procedieran al embarque, Rodríguez San Pedro, 1865, II: 462-464. Granda (Madrid, 1984): 562-563. Castro (Madrid, 1994): 7-19. En agosto de 1862 llegaron 200 emancipados, únicos que fueron enviados, aunque durante varios años las instrucciones de Madrid fueron terminantes. García Cantús, 2002: 454-465.

87 Revista Hispano-Americana, 4 / 23 (Madrid, 1865): 504-507.

88 Citado en la comunicación de Manzano al ministro de Ultramar, 15 de febrero de 1867, AHN, Ultramar, legajo 4666.

89 Valiente, 1869: 20.

$90 \mathrm{La}$ correspondencia que muestra el conflicto permanente entre el gobierno de Madrid y los generales Dulce, Lersundi y Manzano en AHN, Ultramar, legajo 4666. 
En septiembre de 1868 un movimiento revolucionario puso fin al reinado de Isabel II y poco después se inició en Cuba un estallido independentista. Los insurrectos adoptaron el principio de abolición, lo cual obligaba al gobierno de Madrid a tomar medidas para evitar que los Estados Unidos reconocieran el estado de beligerancia e intervinieran en el conflicto. En mayo de 1870, el ministro de Ultramar Segismundo Moret escribía al capitán general: «Francia e Inglaterra no nos ayudarán mientras sigamos teniendo esclavos, y esta palabra [esclavitud] da derecho a Norteamérica a mantener suspendida sobre nuestras cabezas una amenaza ${ }^{91}$. Por ello, a pesar de la oposición de los esclavistas cubanos, en julio de 1870 las Cortes aprobaron la Ley Moret, una ley preparatoria para la abolición de la esclavitud. En su artículo V se declaraba libres a todos los esclavos del Estado y a quienes a «título de emancipados estuvieran bajo la protección del Estado». El hecho de que una ley para abolir la esclavitud se ocupara de un grupo jurídicamente libre mostraba, una vez más, que la libertad de los emancipados había sido meramente nominal y que la ordenanza de 1865 había quedado incumplida ${ }^{92}$.

Con la contienda quedó en suspenso la concesión de cartas, que se reanudó en septiembre de 1869 cuando se declararon exentas de la dependencia del gobierno las expediciones aprehendidas en 1841 y 1842; en febrero de 1870, las capturadas entre 1843 y 1849 , y en junio las apresadas entre 1849 y 1853 . La Ley Moret no representaba una novedad, sino la culminación de un proceso ya en marcha, cuyo ritmo se aceleró: el 7 de octubre se concedió su carta a los negros apresados entre 1855 y 1858; el 27, a los que lo habían sido en 1858, 1859 y parte de 1860; en diciembre, a los capturados entre 1862 y 1866, que eran los últimos ${ }^{93}$. En total obtuvieron sus cartas 3.192 emancipados $^{94}$. Pero las autoridades de Cuba les obligaron a contratar su trabajo durante seis años por un salario inferior al del mercado y, además, les forzaron a que consintieran que sus cartas de libertad fueran custodiadas por los amos en garantía del cumplimiento de los contratos, lo que equivalía a sentenciar al emancipado a esclavitud. El gobierno de Madrid se opuso enérgicamente y el 28 de septiembre ordenó que semejante cláusula desapareciera, pero ya se habían firmado

91 Thomas, 1973, 1: 341.

92 Roldán de Montaud, 57 / 169-170 (Madrid, 1982): 638.

93 Caballero de Rodas al ministro de Ultramar, 29 de octubre de 1870. «Gobierno superior político de la provincia de Cuba. Resolución», Gaceta de la Habana, 6 de diciembre de 1870 .

94 Estado demostrativo del número de libertos que han adquirido la libertad por estar comprendidos en los cinco primeros artículos de la ley de junio, Junta Central Protectora de Libertos, 11 de mayo de 1875, AHN, Ultramar, legajo 4882, vol. III y IV, cfr. Corwin, 1967: 249. 
1.777 contratos de aquel tipo. No cabe mayor crítica que las palabras del abolicionista Rafael María de Labra: «Las contratas de 1870 son lisa y llanamente la esclavitud; pero la esclavitud hipócrita y cobarde. Por el ingenioso medio de estos contratos, los emancipados en Cuba volvieron a caer en los moldes de la antigua servidumbre, y ésta fue una manera hábil de eludir los preceptos de la ley preparatoria [...]. ¿Se necesita el trabajo forzoso siquiera sea retribuido? Pues no hablemos de libertad» ${ }^{95}$.

\section{BIBLIOGRAFÍA}

Adderley, Rosanne M., "New negroes from Africa»: slave trade abolition and free African Settlement in the Nineteenth-Century Caribbean, Bloomington, Indiana University Press, 2006.

Aimes, Huber H., A History of Slavery, 1511 to 1868, Nueva York, Octagon Books, 1967.

Aparisi y Guijarro, Antonio, Defensa del señor don José Toral (en la causa de supuesto plagio de bozales pertenecientes a la expedición Agüica, apresada el 12 de noviembre de 1863 en la isla de Cuba, hallándose Toral de teniente de la guardia civil y a las órdenes del ex-teniente gobernador de Colón, don José Argüelles), Madrid, Imprenta a cargo de A. Escamez, 1888.

Arnalte, Arturo, «Cónsules, comerciantes y negreros (españoles en Sierra Leona en el siglo XIX)», Estudios Africanos, X / 18-19 (Madrid, 1996): 65-79.

Arnalte, Arturo, Los últimos esclavos de Cuba. Los niños cautivos de la goleta Batans, Madrid, Alianza Editorial, 2001.

Bethell, Leslie, «The mixed Commissions for the Suppression of the Transatlantic Slave Trade in the Nineteenth Century», Journal of African History, 80 (Londres, 1966): 79-93.

Carter, Marina, The last slaves: liberated Africans in 19th century Mauritius, Port Luis, Centre for Research on Indian Ocean Societies, 2003.

Castro, Mariano de, «Fernando Poo y los emancipados de La Habana», Estudios Africanos 3 / 14-15 (Madrid, 1994): 7-19.

Conrad, Robert, «Neither Slave nor Free: The Emancipados of Brazil, 1818-1868», The Hispanic American Historical Review, 53 / 1 (Durham, 1973): 50-70.

Corwin, Arthur F., Spain and the abolition of slavery in Cuba: 1817-1886, Austin-Londres, University of Texas Press, 1967.

95 Labra, 1873: 19-22. 
Cuadro estadístico general que demuestra la población total de la isla de Cuba, La Habana, Imprenta del Gobierno, 1862.

Erénchun, Félix, Anales de la isla de Cuba: diccionario administrativo, económico, estadístico y legislativo, La Habana, Imprenta La Habanera, 1857-1861, 4 vols.

Estorch, Miguel, Apuntes para la historia sobre la administración del Marqués de la Pezuela en Cuba, desde 3 de diciembre de 1853 hasta 21 de septiembre de 1854, Madrid, Imprenta de Manuel Galiano, 1856.

Ferrer de Couto, José, Los negros en sus diversos estados y condiciones tales como son, como se supone que son y cómo deben ser, Nueva York, Hallet Breen, 1864.

Figuera, Fermín, Estudios sobre la isla de Cuba: la cuestión social, Madrid, Imprenta del Colegio de Sordo-Mudos y de Ciegos, 1866.

Fontana, Josep, «El problema de los "emancipados" cubanos ante el Consejo de Estado español (1828)», Revista de la Biblioteca Nacional José Martí, 3. época, XVII / 2 (La Habana, 1975): 89-98.

Franco, José Luciano, El comercio clandestino de esclavos, La Habana, Ciencias Sociales, 1980 .

Gallotti Mamigonian, Beatriz, «Revisitando o problema da "transição para o trabalho livre" no Brasil: a experiência dos africanos livres», Manuel Florentino, (ed.), Tráfico, cativeiro e liberdade (Rio de Janeiro, séculos XVII-XIX), Río de Janeiro, Civilização Brasileira, 2005: 389-417.

Gallotti Mamigonian, Beatriz, "Conflicts over the Meanings of Freedom. The Liberated Africans' Struggle for Emancipation in Brasil, 1840s-1860s», Rosemary Brana-Shute, et al. (eds.), Paths to freedom: Manumission in the Atlantic World, Columbia, S.C., University of South Carolina Press, 2009a: 236-263.

Gallotti Mamigonian, Beatriz, «In the Name of Freedom: Slave Trade Abolition, the Law and the Brazilian Branch of the African Emigration Scheme (Brazil-British West Indies, 1830s-1850s)», Slavery \& Abolition, 30 / 1 (Londres, 2009b): 41-66.

Grandío Moráguez, Oscar, «Dodo: A Liberated African in nineteenth century Havana», en Liberated Africans as Human Legacy of Abolition: An international workshop to mark the bicentennial of British and American abolitions of the slave trader Berkeley, 2008.

García Cantús, M. ${ }^{a}$ Dolores, Fernando Poo: una aventura colonial española en el África occidental, 1778-1900, Tesis doctoral, Universidad de Valencia, 2002.

Granda, Germán de, «Negros emancipados cubanos en Fernando Poo», Revista de Indias, LIV / 174 (Madrid, 1984): 559-566.

Gutiérrez de la Concha, José, Memoria sobre el ramo de los emancipados de la Isla de Cuba, Madrid, La América, 1861. 
Hernández Sánchez Barba, Mario, «David Turnbull y el problema de la esclavitud en Cuba», Anuario de Estudios Americanos, XIV (Sevilla, 1957): 241-329.

Humboldt, Alejander von, The Island of Cuba, Nueva York, Jackson, 1856.

James, Anand, The emigration of liberated Africans to British Guiana, 1841-1852, Turkeyen, University of Guyana, 1991.

Kiple, Kenneth, F., Blacks in colonial Cuba (1774-1899), Gainesville, University Presses of Florida, 1976.

Klein, Herbert, La esclavitud africana en América latina y el Caribe, Madrid, Alianza Editorial, 1986.

Labra, Rafael María de, La abolición de la esclavitud en el orden económico, Madrid, Noguera, 1873.

López de Letona, Antonio, La isla de Cuba: reflexiones sobre su estado social, politico y económico; su administración y gobierno, Madrid, Imprenta de M. J. Ducazal, 1865.

Madden, Richard R., Poems by a Slave in the Island of Cuba, Recently Liberated, Londres, T. Ward and Co., 1840.

Madden, Richard R., The island of Cuba: its resources, progress, and prospects, considered in relation especially to the influence of its prosperity on the interests of the British West India Colonies, Londres, C. Gilpin, 1849.

Martínez Alier, Verena, Marriage, Class and Color in Nineteenth-Century Cuba. A Study of Racial Attitudes and Sexual Values is a Slave Society, Cambridge, Cambridge University Press, 1979.

Martínez-Fernández, Luis, «The Havana Anglo-Spanish Mixed Commission for the Suppression of the Slave Trade and Cuba's Emancipados», Slavery and Abolition, 16 / 2 (Londres, 1995): 205-225.

Martínez-Fernández, Luis, Fighting Slavery in the Caribbean. The Life and times of a British Family in Nineteenth-Century Cuba, Nueva York, M. E. Sharpe, 1998.

Moreno Fraginals, Manuel, El Ingenio. Complejo económico social cubano del azúcar, La Habana, Ciencias Sociales, 1978, 3 vols.

Murray, David R., Odious Commerce: Britain, Spain and the Abolition of the Cuban Slave Trade, Cambridge, Cambridge University Press, 1980.

Ortiz, Fernando, Los negros esclavos, La Habana, Editorial de Ciencias Sociales, 1975.

Paquette, Robert L., Sugar is made with blood: the Conspiracy of La Escalera and the conflict between empires over slavery in Cuba, Middletown, Conn., Wesleyan University Press, 1988. 
Pérez de la Riva, Juan (ed.), Correspondencia reservada del Capitán General Don Miguel Tacón con el Gobierno de Madrid: 1834-1836, La Habana, Consejo Nacional de Cultura-Biblioteca Nacional José Martí, 1963.

Pezuela, Jacobo de la, Diccionario geográfico, estadístico, histórico de la isla de Cuba, Madrid, Imprenta del Establecimiento del Mellado, 1863-1866, 4 vols.

Pezuela, Jacobo de la, Historia de la isla de Cuba, Madrid, Bailly-Baillière, 1868-1878, 4 vols.

Philip, Jacqueline, L'Esclavage à Cuba au XIXe siècle d'après les documents de L'Archivo Histórico Nacional de Madrid, París, Éditions L'Harmattan, 1998.

Piqueras, José Antonio (ed.), Trabajo libre y coactivo en sociedades de plantación, Madrid, Siglo XXI, 2009.

Rodríguez San Pedro, Joaquín, Legislación ultramarina concordada y anotada, Madrid, Imprenta de Viota, Cubas y Vicente, 1865-1869, 16 vols.

Roldán de Montaud, Inés, «Origen evolución y supresión del grupo de negros emancipados en Cuba (1817-1870)», Revista de Indias, 57 / 169-170 (Madrid, 1982): 559-641.

Sanromá, Joaquín M. ${ }^{a}$, La esclavitud en Cuba: discurso pronunciado en la conferencia del día 26 de febrero de 1872, Madrid, Secretaría de la Sociedad Abolicionista Española, 1878.

Shlomowitz, Ralph, Mortality and voyages of liberated Africans to the West Indies, 1841-1867, Bedford Park, Flinders University of South Australia, 1989.

Schuler, Monica, "Alas, alas, Kongo»: a social history of indentured African immigration into Jamaica, Baltimore, John Hopkins University Press, 1980.

Schuler, Monica, «Liberated Africans in nineteenth century Guyana», en Brian L. Moore et al. (eds.), Slavery, freedom and gender: the dynamics of Caribbean societies, Jamaica, University of the West Indies Press, 2001: 133-160.

Thomas, Hugh, Cuba: la lucha por la libertad 1762-1970 - I De la dominación española a la dominación norteamericana, 1762-1909, Barcelona, Grijalbo, 1973.

Thompson, Alvin, Unprofitable Servants: Crown Slaves in Berbice, Guiana 1803-1831, Mona, Jamaica, University of the West Indies Press, 2002.

Turnbull, David, Travels in the West with Notices of Porto Rico and the Slave Trade, London, Longmans, 1840.

Urban, Stanley C., «The Africanization of Cuba Scare, 1853-1855», The Hispanic American Historical Review, 37 / 1 (Durham, 1957): 29-45.

Valiente, Porfirio, Réformes dans les îles de Cuba et de Porto-Rico, París, Imprimerie Centrale des Chemins de Fer, A. Chaix et Cie., 1869.

Varella, Claudia, Esclavos a sueldo, la coartación cubana en el siglo XIX, Tesis doctoral, Universitat Jaume I, 2010. 
Zamora y Coronado, José M., Biblioteca de legislación ultramarina, Madrid, Alegría y Charlain, 1844-1849, 7 vols.

Fecha de recepción: 3-5-2010

Fecha de aceptación: 19-7-2010

\section{IN THE BLURRED BOUNDARIES \\ OF FREEDOM: THE CASE OF LIBERATED AFRICANS IN CUBA, 1817-1870}

In this article we study the group of Africans that were taken to Cuba to be turned into slaves and were declared legally free due to the application of international treaties and the pressure of British abolitionist groups because the ship they were being transported on was captured. However, the so-called emancipated blacks, approximately 26,000, were assimilated as slaves in fear of their becoming a disruptive factor in the social order, due to the need of labor for the sugar plantations and the appearance of a lucrative business for the authorities. This study covers the period from their origin in 1817 to their disappearance in 1870.

Key words: Liberated africans, slavery, abolitionism, Cuba. 